\title{
Contemporary Natural Philosophy and Philosophies-Part 2
}

\author{
Marcin J. Schroeder $1, *(1)$ and Gordana Dodig-Crnkovic 2,3 \\ 1 Global Learning Center, Tohoku University, Sendai 980-8576, Japan \\ 2 Department of Computer Science and Engineering, Chalmers University of Technology, 41296 Gothenburg, \\ Sweden; gordana.dodig-crnkovic@chalmers.se \\ 3 School of Innovation, Design and Engineering, Mälardalen University, 72220 Västerås, Sweden \\ * Correspondence: mjs@gl.aiu.ac.jp
}

Received: 10 September 2020; Accepted: 10 September 2020; Published: 14 September 2020

\begin{abstract}
This is a short presentation by the Guest Editors of the series of Special Issues of the journal Philosophies under the common title "Contemporary Natural Philosophy and Philosophies" in which we present Part 2. The series will continue, and the call for contributions to the next Special Issue will appear shortly.
\end{abstract}

Keywords: natural philosophy; philosophy of nature; naturalism; unity of knowledge

\section{Introduction}

The present Special Issue is Part 2 of the project of a series under the common title Contemporary Natural Philosophy and Philosophies, intended as a venue for publishing the results of research and philosophical reflection seeking a unified vision of reality threatened by the centrifugal forces of growing specialization. In the Introduction to Part 1, the project was presented within the mission of the journal Philosophies: "From the Philosophies program [1], one of the main aims of the journal is to help establish a new unity in diversity in human knowledge, which would include both 'Wissen' (i.e., 'Wissenschaft') and 'scirre' (i.e., 'science'). 'Wissenschaft' (the pursuit of knowledge, learning, and scholarship) is a broader concept of knowledge than 'science', as it involves all kinds of knowledge, including philosophy, and not exclusively knowledge in the form of directly testable explanations and predictions. The broader notion of scholarship incorporates an understanding and articulation of the role of the learner and the process of the growth of knowledge and its development, rather than only the final product and its verification and validation. In other words, it is a form of knowledge that is inclusive of both short-term and long-term perspectives; it is local and global, critical and hypothetical (speculative), breaking new ground. This new synthesis or rather re-integration of knowledge is expected to resonate with basic human value systems, including cultural values" [2].

We would also like to give place in this modern Natural Philosophy to the human in the natural world, both as an active subject and as an integral part of nature, for whom the world comes as an interface [Ref. Otto Rössler, Endophysics: The World as an Interface]. Separation between human and nature, thought and feeling, rational and intuitive, knowledge how and knowledge that embodiment and abstraction, physical and mathematical relations to the world have led to the compartmentalization of human reality in various non-communicating domains. All should have place in this new synthetic network of knowledges under the umbrella of Contemporary Natural Science, in which there is place for the whole human and natural world in coexistence and co-creation.

Part 1 brought an excellent collection of 23 articles (listed in Appendix A) addressing the ideas of the revitalization, revival or recreation of Natural Philosophy, naturalization of some domains of inquiry, or presenting examples of research carried out in the spirit of Natural Philosophy published in 
book format [3]. Part 2 was announced simply as a continuation of this effort, and we are happy and proud to present the next collection of 10 contributions.

\section{Contributions to Part 2}

The contributions offered in Part 2 are steps toward a better understanding of reality and of the way to carry out the inquiry so that we have a broader perspective without losing the unified vision or striving even for achieving a higher level of unification. Even though the papers constituting Part 2 were written independently, upon close inspection, we can identify a thread which binds them into a discourse on the relation between knowing (episteme) and existence (ontos) sometimes as if one paper was intended as a response to another.

The two entirely independent papers, Matching a Trope Ontology to the Basic Formal Ontology by Richard de Rozario and Breakthrough Knowledge Synthesis in the Age of Google by Ronald B. Brown address the central issue of Contemporary Natural Philosophy of the unification of knowledge in the practical context of the present information technology $[4,5]$.

The first of the papers Matching a Trope Ontology to the Basic Formal Ontology by Richard de Rozario is focused on applied ontology which, as the author writes "is as much philosophy as engineering". The main difference between the applied and original form of ontology in the theoretical aspect of the former is that it frequently restricts its attention to more specific conceptual frameworks of particular knowledge disciplines. It is justified by its engineering function to provide methods of combining large databases and developing software working with such combination. From this point of view, applied ontology gives practical tools for the implementation of the goals of Contemporary Natural Philosophy and can also serve as its quasi-empirical field.

The subject of this paper is the relation between Basic Formal Ontology (BFO) and trope ontology. It provides a logical matching, identifies key ontological issues that arise, and concludes with general observations about the matching, such as that matching of universals is generally straightforward, but not the matching between relations. The issues addressed in the paper seem analogical to those which appear in the ontological discussions of the forms of realism, in particular, in the context of structural realism.

The second paper, Breakthrough Knowledge Synthesis in the Age of Google by Ronald B. Brown could be, by analogy to the first, understood as applied epistemology studying a web-based knowledge synthesis method relevant in today's information technology environment with its easy access to online interactive tools and an expansive selection of digitized peer-reviewed literature. The paper offers an innovative method of synthesis based on a grounded theory methodology to organize, analyze, and combine concepts from an intermixed selection of quantitative and qualitative research, inferring an emerging theory or thesis of new knowledge. We can find, in the conclusion of the paper, the statement "Breakthrough knowledge has been shown to occur most often when prior knowledge is mixed with current knowledge." The two papers have basically similar goals, but they differ in the focus on ontological, respectively epistemological issues.

There are two other papers in the collection of Part 2, this time by the same authors but with possibly different roles in research or writing indicated by the reversed order of names which present studies of knowledge from the perspective of neuro-psychology. While the papers reported before had, as their objectives, fostering the integration of human knowledge by the use of information technology, the two papers reported now are more oriented towards the understanding of knowledge as purely human capacity.

The first of the papers A Cognitive Perspective on Knowledge How: Why Intellectualism Is Neuro-Psychologically Implausible by Andreas Stephens and Cathrine V. Felix defends the thesis of the fundamental distinction between "knowledge how" and "knowledge that" and provides empirically backed refutation of the claims (for instance of Stanley-style intellectualism) that knowledge how can be reduced to knowledge that [6]. Moreover, the authors demonstrate that the distinction leads to neuro-psychologically plausible understanding of knowledge. 
The second paper A Naturalistic Perspective on Knowledge How: Grasping Truths in a Practical Way by Cathrine V. Felix and Andreas Stephens is on a similar subject of the distinction between knowing how and knowing that, this time in the elaborated perspective of the practical consequences of knowledge [7]. The authors argue that a plausible interpretation of cognitive-science input concerning knowledge-even if one accepts that knowledge how is partly propositional-must involve an element of knowing how to act correctly upon the proposition, and this element of knowing how to act correctly cannot, itself, be propositional.

The paper De Libero Arbitrio-A Thought-Experiment about the Freedom of Human Will by Johannes Schmidl, although at first sight is on a very different subject of free will, has an indirect affinity to the previously reported paper in its focus on action [8]. The former paper relates knowing how to human action which, as the authors demonstrate, makes it distinct from knowing that. The paper reported now is about the issue of the distinction between human action understood as an expression of the free will and behavior determined in biological or physiological terms which of course reduces the role of knowledge how to biological process which can be described in propositional form, i.e., knowing that. Schmidl defends irreducibility using a thought-experiment which demonstrates that a subjective consciousness can break any forecast about its physical state independently of the method of its detection, which refutes the claims about its purely deterministic role. The thought-experiment picks up on an idea of the philosopher Alvin I. Goldman.

The paper Natural Morphological Computation as Foundation of Learning to Learn in Humans, Other Living Organisms, and Intelligent Machines by Gordana Dodig-Crnkovic adds yet another dimension and a wider context to the study of knowledge not restricted anymore to its form of exclusively human capacity [9]. Dodig-Crnkovic considers the integrative view of the natural, the artificial, and the human-social knowledge and practices. She gives the learning process a central role for acquiring, maintaining, and managing knowledge, both theoretical and practical. The paper explores the relationships between the present advances in understanding of learning in the sciences of the artificial (deep learning, robotics), natural sciences (neuroscience, cognitive science, biology), and philosophy (philosophy of computing, philosophy of mind, natural philosophy).

Dodig-Crnkovic explores the question about the inspiration from nature, specifically its computational models such as info-computation through morphological computing for the development of machine learning and artificial intelligence, and the question about how much, on the other hand, models and experiments in machine learning and robotics can motivate, justify, and inform research in computational cognitive science, neurosciences, and computing nature.

The central idea of the potential contribution to the design for a system to reach human-level intelligence can be understanding of the mechanisms of 'learning to learn' as a step towards deep learning with symbolic layer of computation/information processing in a framework linking connectionism with symbolism.

The topic of the computational aspects of knowledge in natural, human, and artificial systems can be associated with another paper What Is Physical Information? by Roman Krzanowski [10]. However, this author's approach gives priority to the physicalist view of information expressed in his attempt to separate the two forms of information qualified as abstract and physical with a focus on the latter, which he describes as information which has an objective existence, a lack of meaning, and which can be quantified. These three features he identifies as characteristics of physical phenomena. In Krzanowski's view, physical information can be expressed as an organization of natural or artificial entities which corresponds to syntactic information, with no function of representing the world (carrying meaning). He also argues that concepts of (abstract) information that are associated with meaning also depend (to a substantial degree) on physical information, in the same way as semantic information in computing is built upon a given syntax.

The traditional approach making the sharp distinction between the physical (expressed as formal) and abstract (expressed as representational) aspects of reality presented in Krzanowski's paper is in strong contrast to the following three papers. The strongest contrast is with the position presented in 
the paper Spurious, Emergent Laws in Number Worlds by Cristian S. Calude and Karl Svozil, which is an excellent example of the innovative methodology fitting the needs of Contemporary Natural Philosophy [11]. Calude and Svozil refer to Heidegger's Fundamental Question of Metaphysics "Why is there anything at all, rather than nothing?" as their point of departure, but their work goes not in the direction of ontology but, rather, epistemology. The paper has been mostly concerned with the formal consequences of existence under the least amount of extra assumptions. Heidegger's existent (physis, nature, or world) is, here, a World Number-a real number presented in the binary form. Calude and Svozil consider philosophical precedents of this view (in the past considered as a plurality, i.e., world built of numbers, not a number), but they are of secondary importance in this work.

Although this might not have been their intention, their view can be associated with Kripke semantics and the concept of possible worlds. Each possible world consists of all mutually, logically consistent true propositions about the world. Then, the actual world is one of the possible worlds. All propositions about the world bound into a conjunction into one proposition which can be numerically encoded into an infinite binary string (for instance, using Gödel's numbers) and we arrive at Calude and Svozil's Number World without sacrificing much of the traditional philosophical convictions. It seems that the authors' way of thinking is guided more by algorithmic considerations than logical, but in either interpretation, the Number World is convincing. However, the next step is more difficult. They consider the patterns within the Number World as natural laws. However, these laws (patterns) are not intrinsic. The analysis carried out by the authors is from the outside, God-like position which comes with the combinatorial methods (e.g., Ramsey theory).

Whether this perspective is acceptable or not for the reader, epistemological consequences it brings are impressive: "As it turns out, existence implies that an intrinsic and sophisticated mixture of meaningful and (spurious) patterns—possibly interpreted as 'laws'—can arise from xáos. The emergent 'laws' abound, they can be found almost everywhere. The axioms in mathematics find their correspondents in the 'laws' of physics as a sort of 'lógos' upon which the respective mathematical universe is 'created by the formal system'. By analogy, our own universe might be, possibly deceptively and hallucinatory, be perceived as based upon such sorts of 'laws' of physics".

The paper Philosophy in Reality: Scientific Discovery and Logical Recovery by Joseph E. Brenner and Abir U. Igamberdiev gives, in some sense, a competing view [12]. While the Number World of Calude and Svozil is governed by classical logic of language (or, if someone prefers, logic of Turing-type computing), Brenner and Igamberdiev make a clear distinction between epistemological logic of language and Logic in Reality. They propose a sublation of linguistic logics of objects and static forms by a dynamic logic of real physical-mental processes designated as the Logic in Reality (LIR). In their generalized logical theory, dialectics (logical reasoning) and semiotics are recovered from reductionist interpretations and reunited in a new synthetic paradigm centered on meaning and its communication. Their theory constitutes a meta-thesis composed of elements from science, logic, and philosophy.

The last paper Contemporary Natural Philosophy and Contemporary Idola Mentis by Marcin J. Schroeder presents his rather idiosyncratic but minimally restrictive view of Contemporary Natural Philosophy to set the stage for a critical review of habits of thought, which can be detected in the present attempts to achieve goals of Contemporary Natural Philosophy within existing scientific and philosophical methodology [13]. Following Baconian tradition, the habits are grouped in the three (non-exclusive and non-exhaustive) categories of the Idols of the Number, the Idols of the Common Sense, and the Idols of the Elephant. Once again, the examples of the idols in the paper can be understood as unintentional critical responses to some papers in Part 2. For instance, the paper provides arguments against the overestimated distinction between the quantitative and qualitative methods of science (as one of the Idols of the Number). One of the Idols of Common Sense is the common misconception regarding the role of definitions obscuring the process of comparison of competing theories based on different conceptual frameworks. Finally, one of the Idols of the Elephant is the tendency to "flatten" the vision of reality. 
Without any intention on the side of editors or contributors the collection can be viewed as a dialog between several distinct, complementary, but also cooperating views on reality and on the ways of its inquiry and the role of humans in this context.

Funding: The editorial work on this SI received no external funding.

Acknowledgments: The Guest Editors would like to express their gratitude to the authors who contributed to this Special Issue and to numerous anonymous peer reviewers whose work helped in improving the quality of published contributions.

Conflicts of Interest: The authors declare no conflict of interest.

\section{Appendix A}

The List of Contributions to Volume 1 of Contemporary Natural Philosophy and Philosophies available at https://www.mdpi.com/books/pdfview/book/1331:

Gordana Dodig-Crnkovic and Marcin J. Schroeder, Contemporary Natural Philosophy and Philosophies. Bruce J. MacLennan, Philosophia Naturalis Rediviva: Natural Philosophy for the Twenty-First Century. Nicholas Maxwell, We Need to Recreate Natural Philosophy.

Stanley N. Salthe, Perspectives on Natural Philosophy.

Joseph E. Brenner, The Naturalization of Natural Philosophy.

Andrée Ehresmann and Jean-Paul Vanbremeersch, MES: A Mathematical Model for the Revival of Natural Philosophy.

Arran Gare, Natural Philosophy and the Sciences: Challenging Science's Tunnel Vision.

Chris Fields, Sciences of Observation.

Abir U. Igamberdiev, Time and Life in the Relational Universe: Prolegomena to an Integral Paradigm of Natural Philosophy.

Lars-Göran Johansson, Induction and Epistemological Naturalism.

Klaus Mainzer, The Digital and the Real Universe. Foundations of Natural Philosophy and Computational Physics. Gregor Schiemann, The Coming Emptiness: On the Meaning of the Emptiness of the Universe in Natural Philosophy. Koichiro Matsuno, Temporality Naturalized.

Robert E. Ulanowicz, Dimensions Missing from Ecology.

Matt Visser, The Utterly Prosaic Connection between Physics and Mathematics.

Kun Wu and Zhensong Wang, Natural Philosophy and Natural Logic.

Lorenzo Magnani, The Urgent Need of a Naturalized Logic.

Roberta Lanfredini, Categories and Dispositions. A New Look at the Distinction between Primary and Secondary Properties.

Rafal Maciag, Discursive Space and Its Consequences for Understanding Knowledge and Information.

Harald Atmanspacher and Wolfgang Fach, Exceptional Experiences of Stable and Unstable Mental States, Understood from a Dual-Aspect Point of View.

Włodzisław Duch, Hylomorphism Extended: Dynamical Forms and Minds.

Robert Prentner, The Natural Philosophy of Experiencing.

Robert K. Logan, In Praise of and a Critique of Nicholas Maxwell's In Praise of Natural Philosophy: A Revolution for Thought and Life.

\section{References}

1. Schroeder, M.J. The Philosophy of Philosophies: Synthesis through Diversity. Philosophies 2016, 1, 68. [CrossRef]

2. Dodig-Crnkovic, G.; Schroeder, M.J. Contemporary Natural Philosophy and Philosophies. Philosophies 2018, 3, 42. [CrossRef] 
3. Dodig-Crnkovic, G.; Schroeder, M.J. (Eds.) Contemporary Natural Philosophy and Philosophies—Part 1; MDPI: Basel, Switzerland, 2019. Available online: https://www.mdpi.com/books/pdfview/book/1331 (accessed on 10 September 2020).

4. De Rozario, R. Matching a Trope Ontology to the Basic Formal Ontology. Philosophies 2019, 4, 40. [CrossRef]

5. Brown, R.B. Breakthrough Knowledge Synthesis in the Age of Google. Philosophies 2020, 5, 4. [CrossRef]

6. Stephens, A.; Felix, C.V. A Cognitive Perspective on Knowledge How: Why Intellectualism Is Neuro-Psychologically Implausible. Philosophies 2020, 5, 21. [CrossRef]

7. V. Felix, C.; Stephens, A. A Naturalistic Perspective on Knowledge How: Grasping Truths in a Practical Way. Philosophies 2020, 5, 5. [CrossRef]

8. Schmidl, J. De Libero Arbitrio-A Thought-Experiment about the Freedom of Human Will. Philosophies 2020, 5, 3. [CrossRef]

9. Dodig-Crnkovic, G. Natural Morphological Computation as Foundation of Learning to Learn in Humans, Other Living Organisms, and Intelligent Machines. Philosophies 2020, 5, 17. [CrossRef]

10. Krzanowski, R. What Is Physical Information? Philosophies 2020, 5, 10. [CrossRef]

11. Calude, C.S.; Svozil, K. Spurious, Emergent Laws in Number Worlds. Philosophies 2019, 4, 17. [CrossRef]

12. Brenner, J.E.; Igamberdiev, A.U. Philosophy in Reality: Scientific Discovery and Logical Recovery. Philosophies 2019, 4, 22. [CrossRef]

13. Schroeder, M.J. Contemporary Natural Philosophy and Contemporary Idola Mentis. Philosophies 2020, 5, 19. [CrossRef]

(C) 2020 by the authors. Licensee MDPI, Basel, Switzerland. This article is an open access article distributed under the terms and conditions of the Creative Commons Attribution (CC BY) license (http://creativecommons.org/licenses/by/4.0/). 